\title{
Growing Up With Cerebral Palsy: Contemporary Challenges of Healthcare Transition
}

\author{
Maryam Oskoui
}

\begin{abstract}
Cerebral palsy is traditionally known as a major cause of chronic disability in childhood. With advances in neonatal care and improved survival, the majority of adolescents with cerebral palsy require ongoing services into adulthood. This paper highlights some of the challenges in their transition from pediatric to adult healthcare and proposes key elements to ensure a smooth transition process.
\end{abstract}

RÉSUMÉ: Défis actuels de la transition entre les soins de santé pédiatriques et adultes des patients atteints de paralysie cérébrale. La paralysie cérébrale est connue traditionnellement comme une cause majeure de handicap chronique chez l'enfant. Avec les progrès des soins en néonatologie et l'amélioration de la survie, la majorité des adolescents atteints de paralysie cérébrale nécessitent des services à l'âge adulte. Cet article souligne certains des défis rencontrés au moment de la transition entre les soins pédiatriques et les soins adultes et propose des éléments clés pour assurer un processus de transition harmonieux.

Can. J. Neurol. Sci. 2012; 39: 23-25

\section{Changing trends in the prevalence of cerebral palsy (CP)}

Systematic reviews on the prevalence of $\mathrm{CP}$ among children report a median of 2.4 per 1000 children, which has been fairly stable among various demographics. ${ }^{1}$ In Canada only two studies have focused on the prevalence of $\mathrm{CP}$ in the general population of children, both using administrative databases (ICD-9 codes). The first study from Alberta reports on a birth cohort from 1985 to 1989 , with a prevalence of 2.57 per 1000 children eight years of age. ${ }^{2}$ The second study from British Columbia reports on a birth cohort from 1991 to 1995 , with a prevalence of 2.68 per 1000 live births. ${ }^{3}$

Studies on the prevalence of CP among premature survivors have shown mixed results on trends for increased prevalence over time, coinciding with the improved survival of extreme premature newborns. There have been four studies in Canada following prospective cohort of neonatal intensive care unit survivors in Alberta, Nova Scotia, Quebec and Ontario. ${ }^{4-7}$ Of these, two found an increased prevalence ${ }^{4,5}$ while two found that the prevalence remained stable despite increased survival in the post surfactant era ${ }^{6,7}$. The worldwide literature also shows a mix of findings, with evidence for decreased prevalence and severity in very low birth weight infants..$^{8-10}$ The first 'special care baby units' were established in the 1950s, and surfactant was introduced in the 1980 s, with routine use in most centers in the late 1980s and antenatal steroids in the early 1990s. These advances have contributed to improved survival of premature newborns and the inverse relationship between gestational age and prevalence of CP has been well established. ${ }^{11}$ Whether the prevalence of $\mathrm{CP}$ is stable or changing over time, the characteristics of the population may be changing with different severities, subtypes and co-morbidities. This highlights the importance of population-based patient registries in Canada to better assess the burden of $\mathrm{CP}$ in the Canadian population. ${ }^{12}$ Neonatal graduates of the post surfactant era are only now becoming adults. Furthermore, increased use of prenatal neuroprotective magnesium sulfate in Canada with recent guidelines can potentially decrease the incidence of $\mathrm{CP}$ in premature infants. ${ }^{13}$

\section{Growing up with CP}

Although CP is defined as a static motor disorder, it is superimposed on the dynamic processes of development and aging. ${ }^{14}$ Over $90 \%$ of individuals with $\mathrm{CP}$ live beyond their 18 th birthday. ${ }^{15}$ Adults with $\mathrm{CP}$ require ongoing health services to continue to monitor for needs that were present in childhood. Feeding difficulties, gastroesophagal reflux, constipation, seizures, progressive scoliosis, contractures and dislocations secondary to unremitting spasticity continue to be important medical issues to address. Access to routine care, dental care and screening are also important, such as cardiovascular health, pap smears and mammographies. There are, however, a number of new health issues that emerge in adulthood for this patient

\footnotetext{
From the Department of Pediatrics, Division of Pediatric Neurology, Montreal Children's Hospital, Montreal, Quebec, Canada.

Received June 14, 2011. Final Revisions Submitted July 19, 2011. Correspondence to: Maryam Oskoui, Department of Pediatrics, Division of Pediatric Neurology, Montreal Children's Hospital, 2300 Tupper street, A-512, Montreal, Quebec, H3H 1P3, Canada.
} 
population. Overuse syndromes, chronic pain and fatigue, osteoarthritis and osteoporosis, and an overall decline in mobility have all been reported among adults with CP. ${ }^{16}$

The access to care once individuals are of adult age remains problematic. A recent study in Ontario on health care use patterns among 587 teens and 477 young adults showed a greater rate of outpatient visits among CP patients (x 2.2 in teens, x 1.9 in adults) compared to age-matched peers and a higher rate of hospital admissions (x 4.3 in teens, x 10.6 in adults). Adults with $\mathrm{CP}$ had significantly more visits to general practitioners and significantly fewer visits to specialists than teens with $\mathrm{CP}$, with a trend toward increased number of emergency department visits. ${ }^{17}$ In a report on the burden of neurological diseases in Canada, the Public Health Agency of Canada estimates that total costs associated with CP in 2000-2001 were \$381.8 million, recognizing that there are insufficient data to assess the full impact and explicitly calling for more research in this area. ${ }^{18}$

Looking at the literature on outcomes in adults with CP from 1970 to 2010, a mapping review showed two new important trends. ${ }^{19}$ Studies reporting on the access to and use of health care have only emerged since 1997, showing markedly diminished access after adulthood. There has also been an increased focus on contextual factors (personal, environmental) over time, with four studies published in the 1990 s and 21 studies published since 2000. Such contextual factors are important determinants of quality of life in individuals living with chronic disabilities. ${ }^{20}$ Family functioning, behavioral difficulties, and motivation are reported as important predictors of social-emotional adaptation. These factors among others should be targeted in transition planning.

\section{Transition challenges}

Most institutions transfer patients with $\mathrm{CP}$ to adult care rather than transition them. Transfer is the actual responsibility of care of the patient being moved from a pediatric setting to an adult care setting. Transition is the "purposeful, planned preparation of patients, families and caregivers for transfer of a patient from a pediatric to an adult care setting." ${ }^{21}$ Over the past decade there have been numerous position statements addressing transition as a priority mandate for those caring for youth with special health care needs..$^{21-23}$ The key challenges in transitioning young adults with $\mathrm{CP}$ are common to all individuals living with chronic disabilities having special health care needs. The individual's maturity and cognitive ability, the preparation of the patient and family, and access to specialists and multidisciplinary care as adults are but a few of the key issues.

Although most Canadian medical institutions require transfer of care at 18 years, it is well accepted that age is not the best indicator of preparedness. ${ }^{24}$ The individual's maturity and cognitive ability are important factors to consider, and preparing individuals to become increasingly autonomous in their interaction within their health care environment within a developmental appropriate process is encouraged. Examples include making appointments, taking medications, and actively participating during medical visits. Individuals with significant cognitive impairment who will continue to be fully dependent as adults will need additional consideration for proxy decision making, legal guardianship and estate planning. Preparing patients and families for eventual transfer to adult care includes educating them on their medical condition, their medications and side effects, self-management skills, and learning to navigate the adult health care system. It is especially important for patients and other family members to know their medical history when faced as adults with the reality of aging parents and new health care professionals who are unfamiliar with them. The transition process should focus on preparing these patients and families for a lifecourse, living with a chronic disability and optimizing their full intrinsic potential.

Although ensuring the continuity of healthcare, with routine preventive care, dental care and rehabilitation services is a focus within medical establishments, individuals need to transition in other spheres that may be just as important. These include education and employment, finances and benefits, housing, transportation, leisure activities and relationships. Without preparation, families, patients and even pediatric health care professionals can be reluctant to transfer patients with special healthcare needs to adult care at a critical time when patients are undergoing many transitions in their life that create multiple personal and familial challenges. Pediatric and adult health care environments have traditionally been different in their approach, with pediatric care being more family-centred and paternalistic. Parents worry that their concerns will not be addressed in the adult milieu, that they will no longer be able to advocate effectively for their adult children or navigate an increasingly fragmented health care system on their child's behalf. There is also a bond with the pediatric health care professional who has known the family from the time of initial diagnosis. Difficulty finding a primary care provider is especially a challenge for these patients who would benefit from having a primary care provider to coordinate their care. A multidisciplinary specialized care environment is also needed as a resource, where a coordinated multifaceted team approach helps avoid multiple trips and fragmented care. Specialists and multidisciplinary care clinics for adults with CP are few and far between, and a lack of knowledge or treatment comfort of adult care providers for $\mathrm{CP}$ is often postulated. ${ }^{25,26}$ Adults with $\mathrm{CP}$ also see their access to rehabilitation services progressively diminish over time. A recent study using semi-structured individual interviews with teens and adults with cerebral palsy, spina bifida, and acquired brain injuries of childhood, and their parents, asked them to identify barriers to transition and propose solutions. The top four barriers were: lack of access to healthcare, lack of professional knowledge, lack of information provided, and uncertainty regarding the transition process. ${ }^{27}$ The two simple solutions highlighted were more information and more support throughout the transition process.

\section{Models of transition}

Transition of care is a process incorporating the developmentally appropriate preparation of the patient within their family unit for their eventual transfer to adult care. Effective transfer of patients necessitates communication between healthcare workers and sharing of information, going beyond a simple transfer summary which may not be obtained in time and lacks details of previous investigations and functional status of the patient. Patients with CP can be transferred to a number of different clinical environments: a primary care clinic, a general adult neurology clinic within the community, a subspecialty 
clinic if available, a rehabilitation center, or a joint pediatric and adult healthcare provider clinic. The latter are increasingly favored within various subspecialties, where both the pediatric and adult health care professionals involved see the patients jointly to ensure a smooth transfer of care. However such clinics may not be feasible within most busy practices and may be limited in number and less accessible to those living outside urban centers. Allowing the patient to return to see the pediatric care provider after their initial adult care visit may be a reasonable option, ensuring that there is no gap in care and providing the family with any needed additional resources within their community. Several transition checklists are readily available in the literature and online which can be adapted and used clinically at various ages ${ }^{28,29}$ An evidence-based model and suggested practice guidelines for the transition of youth with disabilities has been elaborated in Ontario, and follow-up on field testing of this model will be of interest. ${ }^{30}$

The important elements of the transition process are to start early and plan ahead, prepare for a lifecourse, and involve families. Benefits of a transition program for individuals with $\mathrm{CP}$ include better continuity of care and information sharing between pediatric and adult care providers, improved patient care and education, and potentially reduced long term health care costs. A transition program also provides physicians and trainees with an educational opportunity to learn about the process and evolving care of adults with $\mathrm{CP}$, with the hope of inspiring some adult care providers to specialize in the care of this evolving and expanding adult population.

\section{ACKNOWLEDGEMENT}

The author thanks NeuroDevNet for the opportunity to present on this topic during the second Annual Brain Development Conference, and Dr. Michael Shevell for his mentorship.

\section{REFERENCES}

1. Hirtz D, Thurman DJ, Gwinn-Hardy K, Mohamed M, Chaudhuri AR, Zalutsky R. How common are the "common" neurologic disorders? Neurology. 2007 Jan;68(5):326-37.

2. Robertson CM, Svenson LW, Joffres MR. Prevalence of cerebral palsy in Alberta. Can J Neurol Sci. 1998 May;25(2):117-22.

3. Smith L, Kelly KD, Prkachin G, Voaklander DC. The prevalence of cerebral palsy in British Columbia, 1991-1995. J Neurol Sci. 2008 July;35(3):342-7.

4. Robertson CMT, Watt MJ, Yasui Y. Changes in the prevalence of cerebral palsy for children born very prematurely within a population-based program over 30 years. JAMA. 2007 27;297 (24):2733-40.

5. Vincer MJ, Allen AC, Joseph KS, Stinson DA, Scott H, Wood E. Increasing prevalence of cerebral palsy among very preterm infants: a population-based study. Pediatrics. 2006 Dec;118(6): e1621-6.

6. Lefebvre F, Glorieux J, St-Laurent-Gagnon T. Neonatal survival and disability rate at age 18 months for infants born between 23 and 28 weeks of gestation. Am J Obstet Gynecol. 1996 Mar;174 (3):833-8

7. Jacobs SE, O'Brien K, Inwood S, Kelly EN, Whyte HE. Outcome of infants 23-26 weeks' gestation pre and post surfactant. Acta Paediatr. 2000 Aug;89(8):959-65.

8. Bhushan V, Paneth N, Kiely JL. Impact of improved survival of very low birth weight infants on recent secular trends in the prevalence of cerebral palsy. Pediatrics. 1993 Jun;91(6): 1094-100.
9. Dolk H, Parkes J, Hill N. Trends in the prevalence of cerebral palsy in Northern Ireland, 1981-1997. Dev Med Child Neurol. 2006 Jun;48(6):406-12.

10. Van Haastert IC, Groenendaal F, Uiterwaal CS, et al. Decreasing incidence and severity of cerebral palsy in prematurely born children. J Pediatr. 2011 Jul;159(1):86-91 e1.

11. Himpens E, Van Den Broeck C, Oostra A, Calders P, Vanhaesebrouck P. Prevalence, type, distribution, and severity of cerebral palsy in relation to gestational age: A meta-analytic review. Dev Med Child Neurol. 2008 May;50(5):334-40.

12. Shevell MI, Dagenais L, Hall N. The relationship of cerebral palsy subtype and functional motor impairment: a population-based study. Dev Med Child Neurol. 2009 Nov;51(11):872-7.

13. Magee L, Sawchuck D, Synnes A, von Dadelszen P. Magnesium sulphate for fetal neuroprotection. J Obstet Gynaecol Can. 2011 May;33(5):516-29.

14. Rosenbaum P, Paneth N, Leviton A, et al. A report: the definition and classification of cerebral palsy April 2006. Dev Med Child Neurol Suppl. 2007 Feb;109:8-14.

15. Strauss D, Brooks J, Rosenbloom L, Shavelle R. Life expectancy in cerebral palsy: an update. Dev Med Child Neurol. 2008 Jul;50 (7):487-93

16. Haak P, Lenski M, Hidecker MJ, Li M, Paneth N. Cerebral palsy and aging. Dev Med Child Neurol. 2009 Oct;51 Suppl 4:16-23.

17. Young NL, Gilbert TK, McCormick A, et al. Youth and young adults with cerebral palsy: their use of physician and hospital services. Arch Phys Med Rehabil. 2007 Jun;88(6):696-702.

18. Canadian Institute for Health Information. The Burden of Neurological Diseases, Disorders and Injuries in Canada Ottawa:CIHI 2007.

19. Kembhavi G, Darrah J, Payne K, Plesuk D. Adults with a diagnosis of cerebral palsy: a mapping review of long-term outcomes. Dev Med Child Neurol. 2011 Jul;53(7):610-4.

20. Majnemer A, Shevell M, Rosenbaum P, Law M, Poulin C. Determinants of life quality in school-age children with cerebral palsy. J Pediatr. 2007 Nov;151(5):470-5,5 e1-3.

21. Blum RW, Garell D, Hodgman CH, et al. Transition from childcentered to adult health-care systems for adolescents with chronic conditions. A position paper of the Society for Adolescent Medicine. J Adolesc Health. 1993 Nov;14(7):570-6.

22. Ziring PR, Brazdziunas D, Gonzalez de Pijem, et al. Transition of care provided for adolescents with special health care needs. Pediatrics. 1996 Dec;98(6):1203-6.

23. Kaufman M, Pinzon J. Transition to adult care for youth with special health care needs. Paediatr Child Health. 2007 Nov;12 (9):785-93.

24. Reiss JG, Gibson RW, Walker LR. Health care transition: youth, family, and provider perspectives. Pediatrics. 2005 Jan;115(1): 112-20.

25. MacDonald N. Finding the way--meeting the needs of adults with childhood-acquired illnesses. CMAJ. 2006 Sep26;175(7):717, 719

26. Wood DL, Kantor D, Edwards L, James H. Health care transition for youth with cerebral palsy. NE Florida Med. 2008;59(4):44-7.

27. Young NL, Barden WS, Mills WA, Burke TA, Law M, Boydell K. Transition to adult-oriented health care: perspectives of youth and adults with complex physical disabilities. Phys Occup Ther Pediatr. 2009;29(4):345-61.

28. Reiss J. The health care transition initiative, University of Florida, Institute for Child Health Policy. Cited on July 18 2011; Available from: http://hctransitions.ichp.ufl.edu/

29. Donkervoort M, Wiegerink DJ, van Meeteren J, Stam HJ, Roebroeck ME. Transition to adulthood: validation of the Rotterdam Transition Profile for young adults with cerebral palsy and normal intelligence. Dev Med Child Neurol. 2009 Jan; 51(1):53-62.

30. Stewart, D, Freeman M, Law M, Healy H, Burke-Gaffney J, Forhan M, Young N, Guenther S. "The best journey to adult life" for youth with disabilities. An evidence-based model and best practice guidelines for the transition to adulthood< http://transitions.canchild.ca/en/OurResearch/bestpractices.asp. [Internet] [Cited 2009 May 28]. 2009. Available from: http://transitions.canchild.ca/en/OurResearch/bestpractices.asp. 